To the Editor,

\title{
Re: Camurati-Engelmann disease
}

Sri Lanka Journal of Diabetes, Endocrinology and Metabolism 2012; 2: 121

I would like to comment on CamuratiEngelmann disease which appeared in your Journal 2011 Aug; 1(1): 54, authored by Pathmanathan S. et al.

This condition has been reported previously in Sri Lanka by Dharmadasa $\mathrm{K}$ et al in the Ceylon Medical Journal, 1981; 26: 178-179. The two patients described in that article, subsequently came under my care at Kurunegala. The daughter of the index patient (case 2) was brought to me because she threatened to commit suicide precipitated by the severe unrelenting pain in the lower limbs. After perusing some literature, I prescribed prednisolone $40 \mathrm{mg}$ daily for one week on a trial basis. The severe bone pains receded completely within one week. I then tailed off the steroids over the next month. She did not have a relapse of the pain even up to 4 years while she was under my care. She married at the age of 18 and was thereafter lost to follow up. The mother who was the index patient mentioned in the aforesaid article had no bone pains and was not given steroids.

Subsequently I corresponded with Dr. Irwin. A. Schafer and Dr. Luigi Luzzatti of the Stanford University School of Medicine in USA in February 1981. They replied that they had two patients with the same disease who had been given steroids, one of whom benefited and the other developed steroid side effects and the steroids were withdrawn.

The purpose of this correspondence is to highlight the first description of this condition in Sri Lanka by Dharmadasa K, et al and to bring to the readers notice that short term steroid therapy may benefit these patients when they have unrelenting bone pain.

\section{H. N. Rajaratnam}

Physician and Endocrinologist 